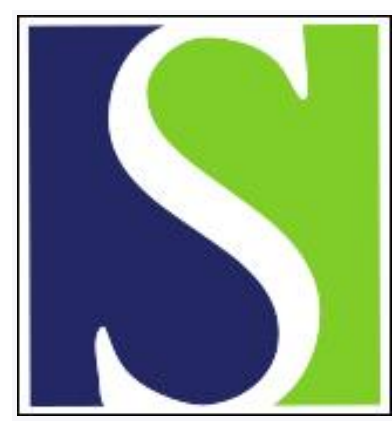

Scand J Work Environ Health 2003;29(1):79-80

https://doi.org/10.5271/sjweh.1021

Issue date: Feb 2003

\title{
Quality of evidence
}

by Carter T

Affiliation: Institute of Occupational Health, University of Birmingham, B15 2TT, United Kingdom. tim.carter@virgin.net

Refers to the following texts of the Journal: 2002;28(5):359-360 2002;28(3):197-204 2002;28(5):358-359

Key terms: evidence; letter to the editor; quality

This article in PubMed: www.ncbi.nlm.nih.gov/pubmed/12630441

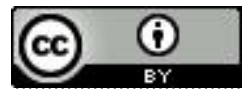




\section{Quality of evidence}

Verbeek and his co-authors (1) recently indicated that rapid searches of biomedical databases can provide useful support for clinical decisions in occupational health. Subsequent correspondence considered the complementary roles of evidence-based approaches and the traditional clinical craft skills based on experience and intuition $(2,3)$. While I would support both contentions in principle, I feel that further exploration is also needed to assess "fitness for purpose" when evidence-based techniques are used to underpin important clinical case management and policy decisions. The key issues to be addressed are "What is the real time taken from framing a question to providing an evidence-based appraisal (there is more to this than just the time to search a database)?", "What quality and depth of appraisal is "fit for purpose' in various situations faced by occupation- al health practitioners?", and "How much of the relevant information is indexed with abstracts on the main biomedical databases?"

I would contrast the approximately 25 hours spent and 1 month of elapsed time that it took me to prepare written appraisals on a series of policy topics (4) against the 30 minutes of search and elapsed time of Verbeek et al (1) to find supporting information for clinical decision making. I would also question the adequacy of a single round of searching and assessment based solely on available abstracts as distinct from search, collection and appraisal of full papers, supplemented by the study of selected material referenced in the first round of papers obtained.

I agree that some incremental improvements in clinical decision making can follow a quick scan of 
abstracts. I would, however, be seriously concerned about the very real limitations of this approach in an area such as occupational health, where decisions are liable to be subjected to regulatory or legal challenge, as well as sometimes leading to actions that can be costly in both personal and financial terms.

I would also worry if such limited searches are indexed as critical appraisals and used by others in contexts other than that in which the question was originally posed, especially if the authority of a source such as the International Commission on Occupational Health was then cited in defense of the subsequent decision.

All this may seem rather negative, but, if a sound evidence base is to be secured to improve the current, rather limited validity of decision making in occupational health, we need a well-developed approach to its quality. This approach will need to take account of the particular social and political framework for occupational health practice when compared with other facets of the health care system.

The teaching of evidence-based approaches and practice with their use should now form a normal part of courses in occupational health practice. It can be fun, and one of the important spin-offs is a valuable skepti- cism about the foundations of much current practice, within which lie the seeds for a better evidence base in the future.

A consensus at an international level is desirable; let's see if one can be achieved!

\section{References}

1. Verbeek JH, van Dijk FJ, Malmivaara A, Hulshof CT, Räsänen K, Kankaanpää EE, Mukala K. Evidence-based medicine for occupational health. Scand J Work Environ Health 2002;28(3):197-204.

2. Larsen AE, Jepson JR. Evidence in occupational medicine [letter]. Scand J Work Environ Health 2002;28(5):358-59.

3. Verbeek J, van Dijk F, Malmivaara A, Hulshof C, Räsänen K, Kankaanpää E, Mukala K. Authors' reply [letter]. Scand J Work Environ Health 2002;28(5):359-60.

4. Carter T. The application of the methods of evidence-based practice to occupational health. Occup Med 2000;50(4):231236.

Tim Carter, FFOM

Institute of Occupational Health

University of Birmingham, B15 2TT, United Kingdom

[E-mail: tim.carter@virgin.net] 